\title{
OPERATIONAL MODAL ANALYSIS AND DAMAGE DETECTION IN FRUIT QUALITY ASSESSMENT USING DIFFERENT METHODS OF PACKAGING
}

\author{
Amer Eissa ${ }^{1}$ A.H. and Gomaa. F. R. ${ }^{2}$
}

\begin{abstract}
1. Department of Agriculture Engineering, Faculty of Agricultural Minoufiya University, Shibin El-Kom, EGYPT. ayman.amereissa@yahoo.com

2. Department of Production Eng.\& Mech. Design, Faculty of Engineering, Minoufiya University,Shibin El-Kom, EGYPT. FawkiaGomaa@yahoo.com
\end{abstract}

\begin{abstract}
An experimental research work in relation to fruit quality assessment is represented in this paper. The demands for high quality fruits require for grower and distributors to set up an integrated quality control system for monitoring the quality of the fruits during transporting.

Vibration simulation carried out to measure the dynamic behaviour of a pear during transporting. The experimental program included the dynamic study on-line. Operational modal parameter estimation was made based on acquired data for three types of packaging methods (Random distribution, Line distributed and Absorber sheet). To asses the dynamic behavior of package and the damage to pear due to transient vibration during transporting and the possible effect due to the position of pear inside the package, utilized the absorber sheet along the floor of transport.

Five identified modes were identified in the frequency range $(0-200 \mathrm{~Hz})$ using two techniques of estimation. Peak picking method (P-P) and robust technique enhanced frequency domain decomposition (EFDD) are applied to avoid harmonic components in application.

A damage identification technique using damage index method has been applied to determine the integrity of the structure (fruit). The results obtained in range $(0-50 \mathrm{~Hz})$ shows that increasing damage volume compared to $(100-200 \mathrm{~Hz})$, may be due to closing harmonic frequency of mechanical element with natural frequency of pear and this need much attention in design the suspension system for fruit transport trucks in attempt to keep the resonance frequencies of fruit away from exciting frequency of rotating system. A comparison of experimental results of three types of packaging shows that absorber sheet is more suitable for packaging. The use of absorber sheets reduced the percentage of damage fruit by (46-59\%). The results obtained in the present research suggest the protective treatment of the fruit with absorber sheet as cushioning package and to design cushioning package to protect an item (fruits) of known strength from known shock
\end{abstract} and vibration.

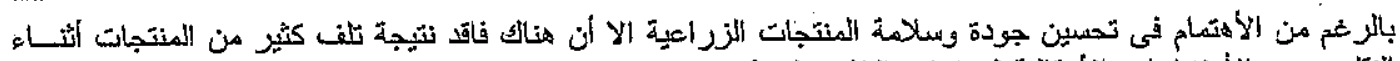

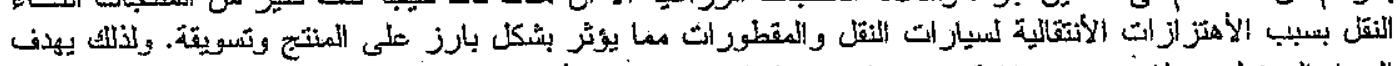

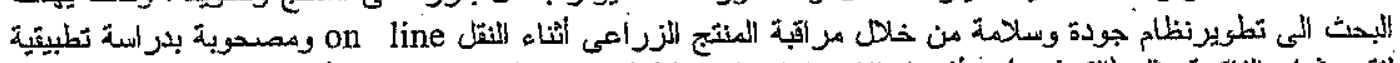

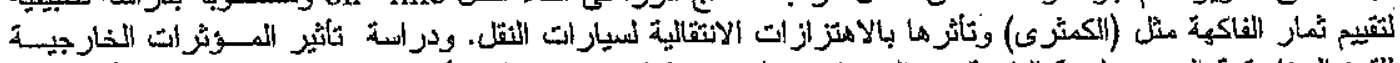

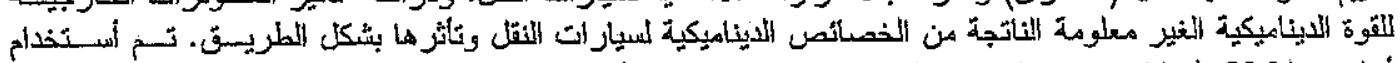

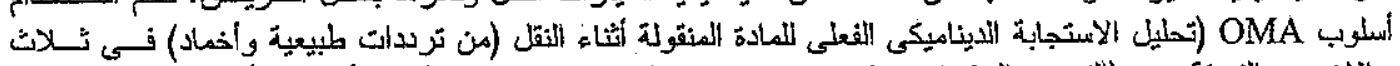

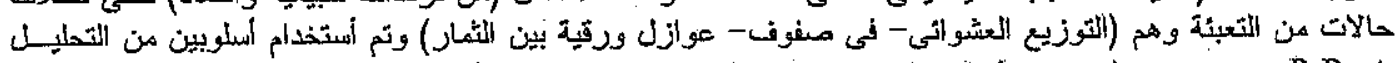

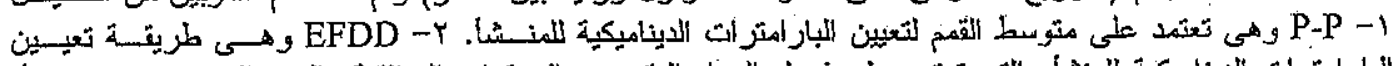

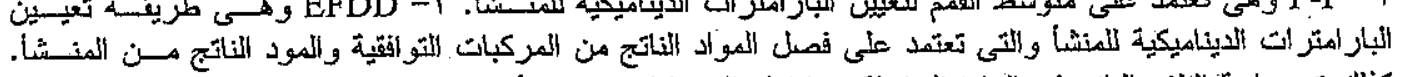

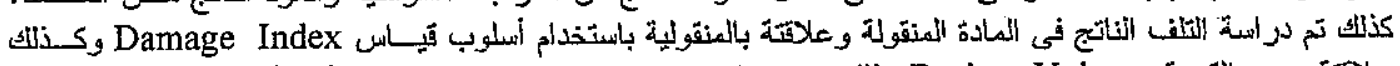

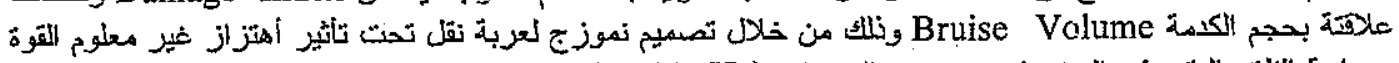

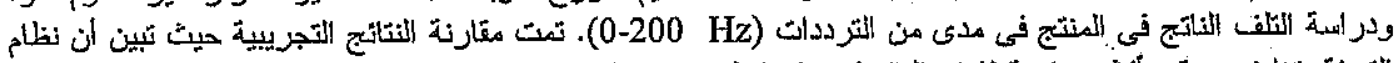

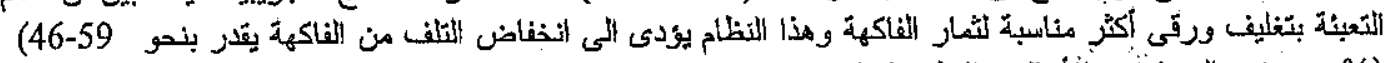

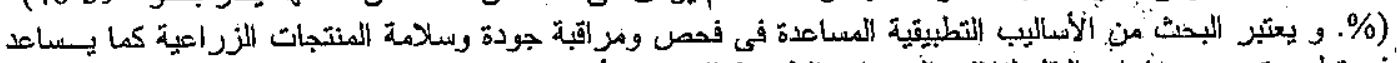

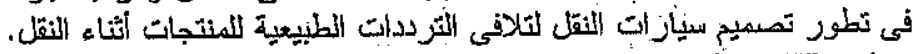

Keywords: Modal testing, Operational Modal Analysis, Damage detection, Packaging, Vibration analysis, Fruit Quality. 


\section{INTRODUCTION}

The quality of fruits can be determined by its external and internal characteristics. The most important external characteristics are the size, shape, smell, appearance and product presentation, and the most important internal characteristics are the taste and texture (see Refs. [1-3]). The flesh firmness is a texture attribute and one of the major fruit quality indicators. The demands for high quality fruits make it necessary for growers and distributors to set up an integrated quality control system for monitoring the quality of the fruits during picking, storage, and distribution. The traditional destructive technique for measuring the firmness is the Magness-Taylor firmness test with penetrometer. This method which is defined in terms of resistance to penetration is, however, destructive and cannot be used for on-line control of fruit quality. Currently, there is a growing interest in non destructive methods for on-line sorting. Many researchers proposed some nondestructive methods based on the dynamic principles, such as the acoustical signal and resonance frequency produced by the machinery knock and shock power, (traditional modal analysis) which utilize eigenfrequency of fruit vibration or shock power to measure its firmness (see Refs. [4-9]). Although the measurements and technologies may be different, their purposes in all studies are to evaluate the Young's modulus of fruit firmness and obtain their relationship. Several non destructive methods for firmness estimation have been developed; the most important ones are based on vibrations [10], ultrasounds [11], compression [12] and impact forces.

Theoretical studies on vibration characteristics of a pear are considered as elastic homogeneous object and the influence of pericarp and the core can be neglected and assumed to be the same as listed in [13-14]. The bottom boundary constraint has been applied. The geometrical model of the pear is meshed by using 3D structural 8 nodes 45 solid elements [15]. Fruits can be modeled as visco-elastic spheres.

Much research has been carried recently out on assessing the effect of vibration during transport on farm produce. The frequencies of transport vibration have been monitored for trucks carrying fresh fruit [16-17]. Moreover, much attention has been paid to assessing mechanical damage to different species of fruit and vegetables during transport, such as potato [18], peaches [19], apples [20-21], loquats [22], and pears [23]. It is thus well known that one of the major causes of mechanical damage to fresh fruit is vibration during transport between farms and retail out lets [24].

Currently, there is a growing interest in damage monitoring for on-line test. The intensity and duration of vibration will determine the severity of damage. In attamped to determine the causes of transmit fruit damage. For this purpose operational modal analysis are procedures to identify modal parameter of structure from the response to unknown random excitation on machine (truck) during operation. The advanced signal processing tool used in techniques allow the inherent properties of fruit structure (resonance frequency, damping ratio and mode patterns) to be determined by only measuring the response of structure without using artificial excitation. This technique has been successfully used in civil engineering structure (building, bridge, and tower) where the natural excitation of the wind is used to extract modal parameters (see Refs. [25-29]). It is now being applied to mechanical and aerospace engineering applications (rotating machinery on-road testing in light testing) [30-31]. The advantage of this technique is that a modal can be generated while the structure is under operating conditions. That is, a modal within true boundary conditions and actual force of vibration levels. The test performed with other applications the measurement technique is identical to (ODS) measurement procedure [32], where, one accelerometer is used as a reference and series of accelerometers for the responses at all degrees of freedom of interests.

For agriculture applications in many existing practical case in addition to the random loads, harmonic excitations are also present due to for instance to the rotating components. If the frequency. of the harmonic components of the input is close to the eigenfrequency of the fruit, damage will occur, and OMA procedure fails to identify the modal parameter accurately (see - Refs. [25, 33-34]). Therefore special attention must be paid to identify and separate harmonic component from structural modes and eliminate the influence of harmonic component in modal analysis, we need robust analysis to solve problem which can not be solved by conventional approach as in (see Refs. [22, 35-36]), they used linear (PSD), and this spectrum can not detect side band frequency if there is closed frequency because of poor resulation through the average result and it need to special correlation detection as in [28] used P-P method and this is good method for light damping and for spaced modes. [22, 37] used natural excitation technique and complex expontional identification) in the presence of harmonic excitation.

In this paper a simulating car modal is designed to investigate the fruit damage during transport, an impact hammer to exit the model and measuring the response through accelerometers with different methods of packaging were employed in simulated transporting test in laboratory as in Fig ( $1 \mathrm{a}, \mathrm{b})$ using robust technique to avoid harmonic component in application this method is EFDD $[29,34]$ and 
compared with P-P method. Three different methods of packing distribution were employed (random, absorber sheet and line distribution). The OMA procedure is based on damage monitoring that could open the door or exploits the automated (fruit and vegetables) damage monitoring towards an automated fruit inspection system.
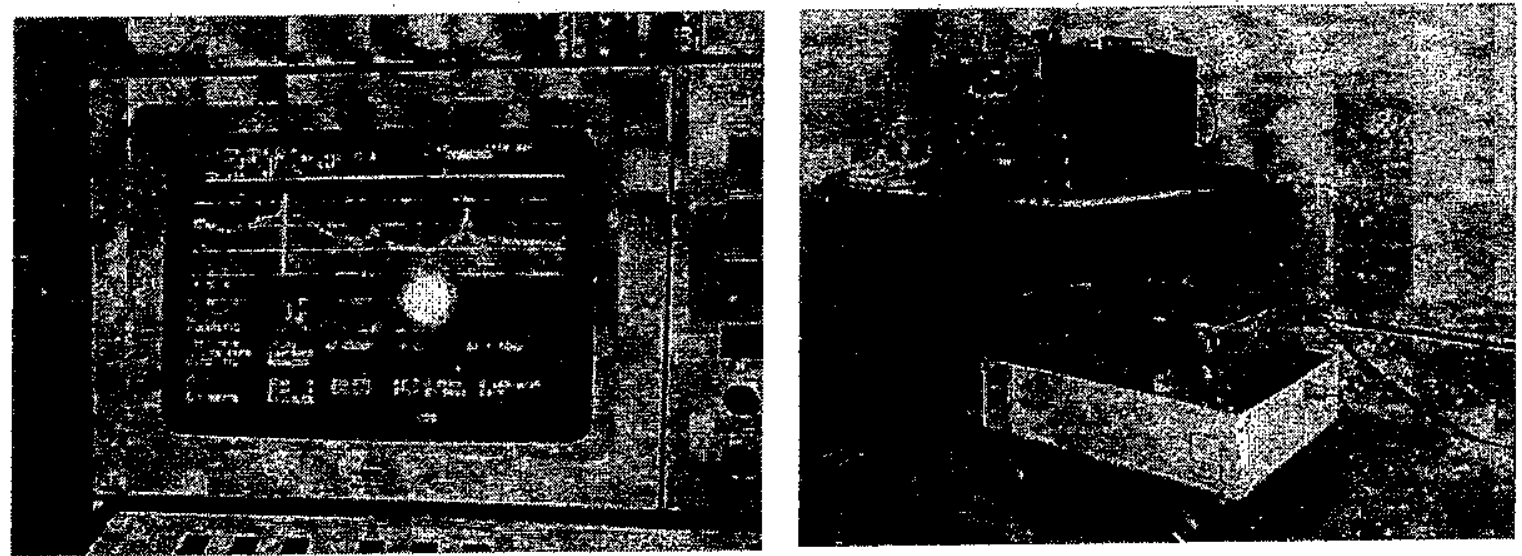

Fig $(1, a)$.Simulating of transporting car and the signal measured on dual channel analyzer.

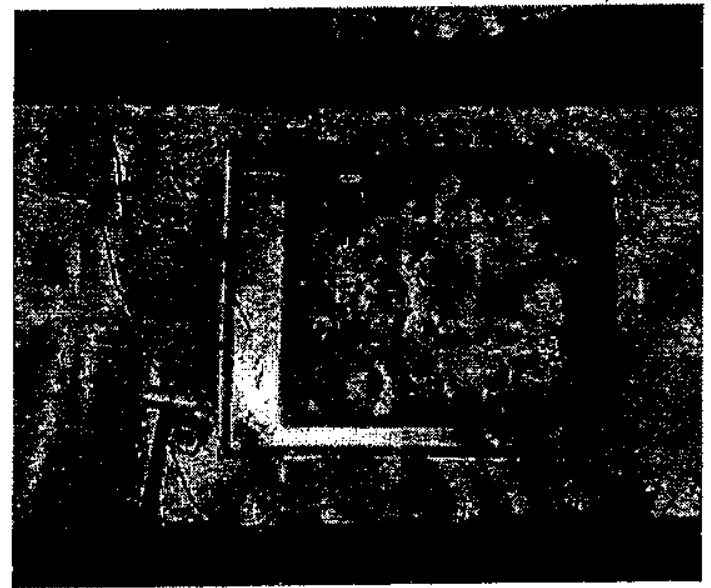

Fig $(\mathbf{1}, \mathbf{b})$. Two accelerometers and impact hammer for measurements.

\section{EXPERIMENTAL PROCEDURE}

An experimental platform is created to investigate health monitoring schemes under (OMA) for a pear using three different methods of packaging and two techniques for operational modal parameters estimation, the methods included.

1- Evaluation of change in modal properties.

2- Evaluation of EFDD (Enhanced Frequency Domain Decomposition) transmittance function with structure subjected to high frequency and compound mode.

\subsection{Specimen Preparation}

Bartlett Pears at commercial maturity, according to the skin color of the fruit, were harvested from a commercial orchard in Sadat, Minoufiya, Egypt. The pears were selected on the basis of uniform color and absence of bruises and disease. All of the pears (about $100 \mathrm{~kg}$ ) were transported to the laboratory

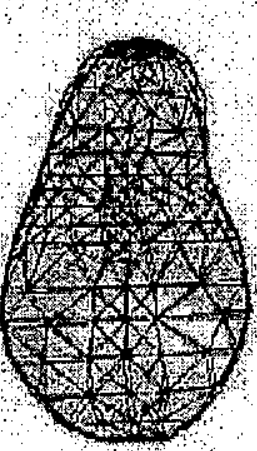

(a)

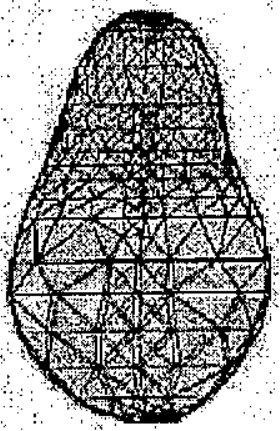

(b)

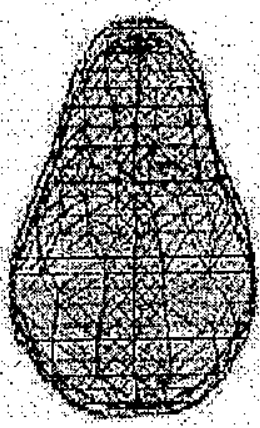

(c)
Fig. (2). Mode shapes of the finite element model. (a) Bending mode); (b) Torsion mode; (c) Compression mode. [15]

within $2 \mathrm{~h}$. According to the commonly used storage method for Bartlett pears. Five fruits were selected randomly from each group and a number was affixed to their stem. Then, the selected pears were transported in a refrigerated box to the laboratory about $2 \mathrm{~h}$ prior to measurements.

The tested pears are taken from the main spring crop (summer 2006, 2007), (Bartlett Pears) were obtained from the "Privet Farm", samples were carefully hand harvested. All samples stored after harvesting to a certain period, and then tested in natural temperature after stored period.

The following material properties were used: density of $1000 \mathrm{~kg} / \mathrm{m}^{3}$, Young's modulus of $2.0 \sim 4.0$ $\mathrm{MPa}$ and was estimated according to [38] and Poisson's ratio was assumed to be 0.3 and volume of $325 \mathrm{~cm}^{3}$ was to analyze the correlation of Young's modulus and frequency. In order to investigate the dynamic behaviors of this type of pear and 
correlation its behavior with geometrical configuration and material characteristics during transporting. The size and dimension as in Fig (2) [15] for the comparison of natural frequency.

\subsection{Simulation Testing}

The evaluation of the pear damage using OMA was carried out simulating road transport in a simple model of "transporting car". To simulate the transportation an impact hammer was used with force transducer. Preliminary vibration measurements were carried out on the floor of the model. As shown Fig (3) during all measurement a small, motor (1200-1500 rpm) is mounted on the frame of the model. This motor which is used as excitation source during OMA has been introduced an amount of unbalance so that the rotation will generate vibration force of the $1^{\text {st }}$ harmonic besides this also a family of higher harmonic is introduced. This was fitted with air ride suspensions for two axles of the model Fig (1a) the front axle was suspended by means of leave springs. Two piezoelectric accelerometers were fixed on the two positions vertical and horizontal as in Fig (1b). The accelerometers were connected to charge amplifier and (FFT) analyzer. The signals were analyzed in the range $(0-200 \mathrm{~Hz})$ using FDD technique [34].

A frequency analysis of the signals was carried using EFDD $[29,34]$ to assess the variability of successive repeated measures of auto and cross correlation function. Since two accelerometers were available for the testing one of these accelerometers is held stationary for the reference during the test Fig (4), where the $i / p$ force remains unknown and may vary between the set-ups. The reference accelerometers is chosen in order to be able to measure very carefully all the global mode of the structure.

To have a laboratory test for OMA evaluation the data analysis in frequency range of interest $(0-200 \mathrm{~Hz})$. Data recorded were Hanning-window with $66.7 \%$ overlap for spectral average.

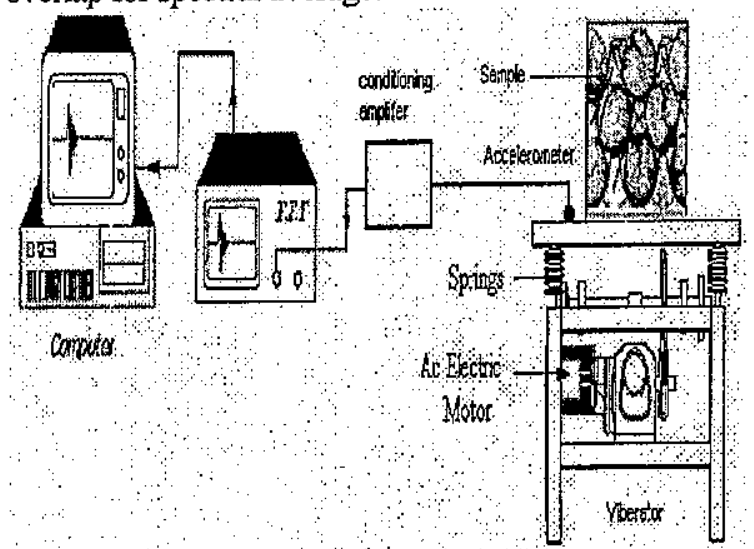

Fig. (3). Schematic layout of the system used for preliminary $\mathrm{t}$ vibration analysis.

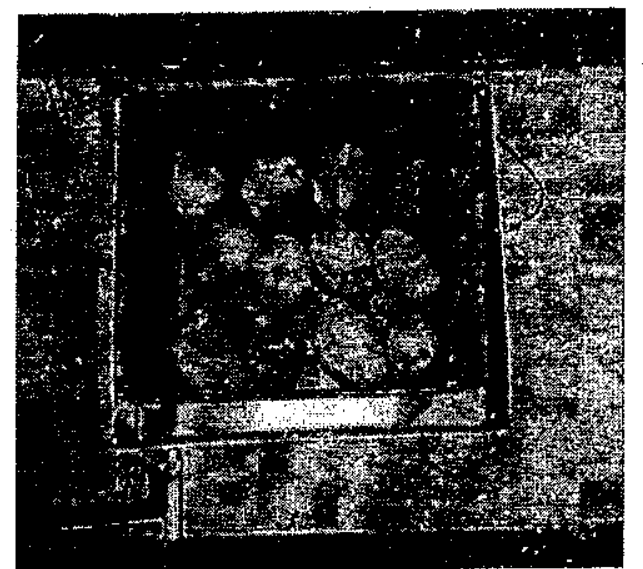

Fig (4). Transmitted force for random distribution package using reference accelerometer.

\subsection{Data Analysis}

Different procedures to obtain modal parameters from the ambient vibration data have been considered (see Refs. [25-29, 33-34]).

The applied forces are unknown; therefore, neither the FRF nor impulse response function can be obtained to determine modal parameters as in classical modal analysis $[33,39]$.

The signal at the fixed accelerometer is used as a reference to determine the FRF and the impulse response function [31].

Two complementary identification methods have been considered in the present work (FDD and EFDD), based on frequency domain analysis using Matlab tool box.

\subsubsection{The first identification method employed is peak-picking (P-P).}

This has been used with success in many other applications (see Refs. $[28,37,40]$ ). This method is based on the fact that when FRF reach a peak at certain frequency it can be associated to the force or to resonance frequency of the structure. Natural frequencies are identified from the peaks of spectral density function

$\omega_{d i}=\sqrt{1-\zeta^{2}} \cdot \omega_{n i}$

The distinguish between peaks associated with the excitation and those associated with resonance frequencies of the structure the coherence function between two signal has a value close to one for the resonance frequencies of the structure. This fact helps to decide as shown in Fig $(5 \mathrm{a}, \mathrm{b})$ which of the frequencies really are the natural frequencies of the structures, the (peak picking methods) (P-P) is based on the assumption that the dynamic resonance peak is determined for each mode. This valid for well separated mode as in Fig $(5$, a) and it's difficult to identify modes very close to each other using this method. 


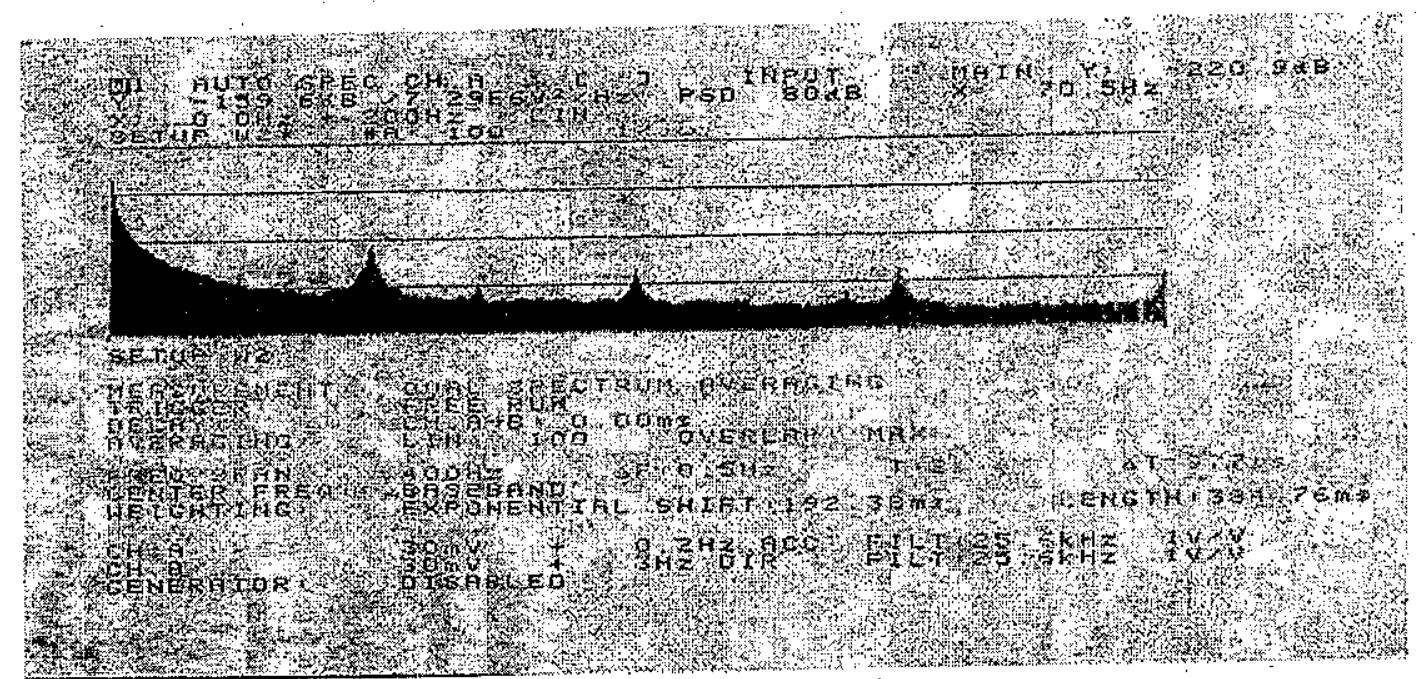

(a)

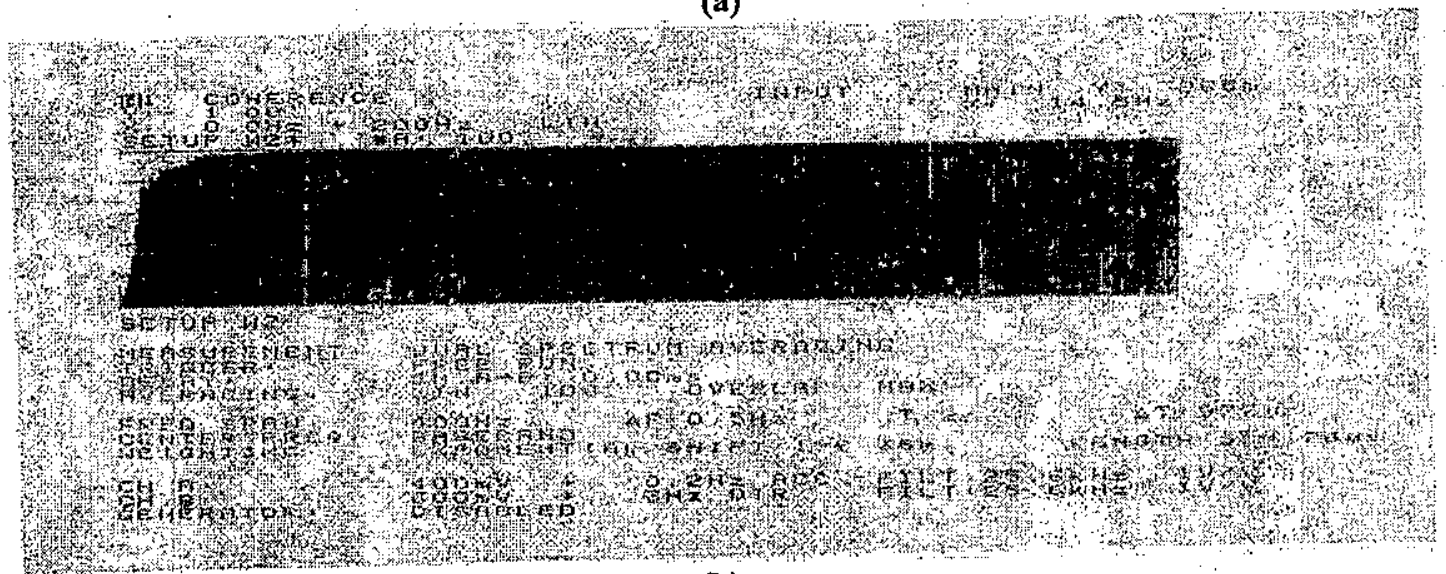

(b)

Fig (5). The resonance frequencies of structure and coherence function between two signals.

\subsubsection{The second identification technique used is the Enhanced Frequency Domain Decomposition (EFDD).}

The technique used in frequency domain [30] which, from a simple form, introduces significant improvement to the peak-picking technique. This method based on a modal decomposition realization of the spectral density matrix. One of the advantages of this method being the possibility of identifying the very close modes.

This nonparametric technique estimates modal parameters directly from signal processing.

FDD technique estimates the modes using singular value decomposition (SVD) of each spectral density matrix. This composition corresponds to (SDOF) identification of the system for each singular value.

The relationship between the input $x(t)$ and the output $y(t)$ can be written in the following form [30].

$$
\left.\left[G_{y y}(j \omega)\right]=[H(j \omega)]^{k}\left[G_{x x}(j \omega)\right] H(j \omega)\right]^{T}
$$

where:

$G_{x x}(j \omega):$ is the input power spectral density matrix that is constant in the case of a stationary Zero mean white noise input

$G_{y y}(j \omega)$ : is the output PSD matrix, and

$H(j \omega)$ : is the FRF matrix as in equation (2).

The FRF matrix can be written in a typical partial fraction from used in classical modal analysis in term poles and residues.

$[H(j \omega)]=\frac{[Y(\omega)]}{[X(\omega)]}=\sum_{k=1}^{m} \frac{\left[R_{k}\right]}{j \omega-\lambda_{c}}+\frac{\left[R_{k}\right]^{*}}{j \omega-\lambda_{k}}$

where: $\lambda_{k}=-\sigma_{k}+j \omega_{d k}$

$\mathrm{m}$ being the total number of modes.

The contribution of the modes at a particular frequency is limited to finite number (usually 1 or 2). The response spectral density matrix can be written as following: 
The final form

$\left[G_{y y}(j \omega)\right]=\sum_{k=s u b(\omega)} \frac{d_{k} \psi_{k} \psi_{k}^{H}}{j \omega-\lambda_{k}}+\frac{d_{k} \psi_{k}^{*} \psi_{k}^{* H}}{j \omega-\lambda_{k}^{*}}$

where:

$\operatorname{sub}(\omega)$ : is the set of modes that contribute at the particular frequency.

$d_{k} \quad$ is a scalar constant

$\psi_{\mathrm{k}} \quad$ is the mode shape vector

$\lambda_{k} \quad$ is the pole of the kth mode.

This final form of the matrix is then decomposed into a set if singular value and singular vector using the singular value decomposition in performed to identify (SDOF) models of the problem.

The (EFDD) technique allows the resonance frequency and damping of a particular mode to extract by computing the auto and cross correlation functions [29].

The (SDOF) power spectral density function identified around resonance peak is returned to time domain using inverse discrete Fourier transform (IDFT) [29].

The natural frequencies is obtained by determining zero crossing time and damping by logarithmic decrements of the corresponding SDOF normalized auto correlation function.

The free-decay time domain function, as in Fig (6) the correlation function of the SDOF system is used to estimate the damping for mode $\mathrm{k}$

$$
\delta_{k}=\frac{2}{p} \operatorname{lin}\left(\frac{r_{o k}}{\left|r_{p k}\right|}\right)
$$

where:

$\mathrm{r}_{\mathrm{ok}}$ is the initial value of the correlation function; $x_{\mathrm{pk}}$ is the Peak ${ }^{\text {th }}$ extrema.

The damping natural frequencies are obtained by regression of the crossing time corresponding to the extrema of correlation function. The undamped natural frequency for mode $\mathrm{k}$ is then

$f_{\mathrm{ok}}=\frac{f_{d k}}{\sqrt{1-\zeta_{k}^{2}}}$

When the SDOF function is estimated using the sbape determined by previous FDD peak picking the latter being used as a reference vector in a correlation analysis based on the Modal Assurance Criteria (MAC). A MAC value is computed between the response, FDD vector and a singular vector for each particular frequency line. If the MAC value of this vector is above a user-specified MAC rejection level, the corresponding singular value is included in the description of the SDOF function. The MAC value describes the degree of correlation between 2 modes (it takes a value between 0 and 1). A good comparison value of these rejection criteria is 0.9
[41]. An average value of the singular vector is then obtained.

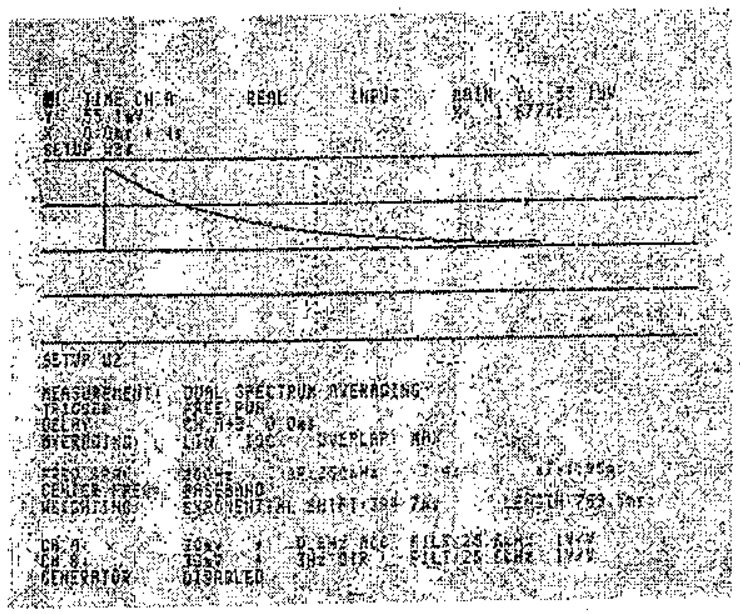

Fig (6). The free decay time domain.

\subsection{Bruise spot evaluation}

After vibration testing, pears were stored for three days at a temperature of $\left(20-22 \mathrm{C}^{\circ}\right)$ for about $24-72 \mathrm{~h}$ to allow full development of the bruise. During this interval, the color of the bruised parts of the fruit flesh changed from the original to brown [42]. The fruit were then cut in the middle of the two bruised spots perpendicularly to the fruit surface and the diameters $(D)$ and depths $(t)$ (in $\mathrm{cm}$ ) of the spots were measured as shown in Fig (7). These were used to calculate the bruise volume of the individual spot based on the formula given by [43];

$V\left(\mathrm{~cm}^{3}\right)=\pi D^{2} \frac{t}{6}$

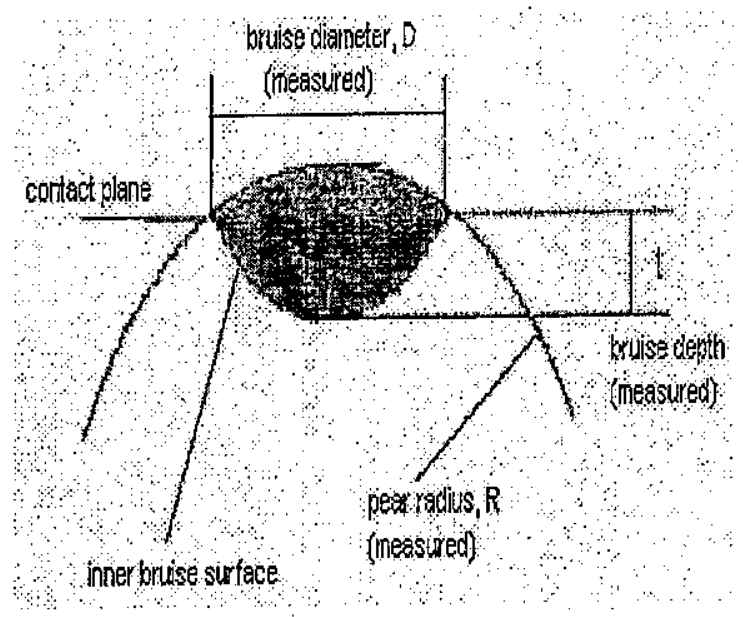

Fig. (7). Bruise volume calculation.

To detect the bruising in tuber the samples were taken to be treated with a chemical solution (the samples were taken and deluging in a catechol for five minutes). The chemical detection material is a catechol [44]. The catechol treatment, applied to the 
outer surface of pear, detects only bruises that break the surface of the pear. Since black spots seldom break the skin, they are not detected by the catechol and tend to be overlooked.

The damage was considered as the visible damage to the human eyes after 24 hours for each test scuffed pears (with surface abrasion damage to skin) and those with flesh damage were separated from each test and there percentages based on the weights of the corresponding dropping were taken as pear mechanical damage at which location or zones of the surface of pear where the damage occurred: (a) Equatorial; (b) peduncular; (c) calycine.

\subsection{Correlations of dynamics characteristics with transmissibility.}

Second-order models [Eq. (9)] were used to fit the observed data. The coefficients of the model were calculated through nonlinear regression also using STATISTICA software:

$Y=b_{0}=b_{1} M+b_{2} P+b_{11} M^{2}+b_{12} M x P+b_{22} P^{2}$

where $Y$ is the dependent variable, $M$ and $P$ are the independent variables; $b_{0}, b_{1}, b_{2}, b_{11}, b_{12}$ and $b_{22}$ are regression coefficients.

\section{RESULTS AND DISCUSSION}

\subsection{Dynamic behavior of pear during transporting.}

The variation of vibration characteristics of this type of pear with the correlation of its behavior and material characteristics was investigated using
(OMA) for three methods of packages. The dynamic behavior of the simulation model of transporting pears are governed by vertical bending and torsion modes, in the frequency range of $(0-200 \mathrm{~Hz})$, five modes have been identified in this frequency range. Table (1) shows the obtained natural frequencies and damping loss factor for two techniques of estimation of the model under the transporting conditions for both three methods of packaging. The first test was carried for random distribution while the second test for line distribution and the third was using absorber sheet for each pear. Very little change appears in the natural frequencies obtained from the three experimental tests, as can be seen from the values shown in Table (1). Damping loss factor may increase up to $20 \%$ when the packing is distributed absorber sheet as compared with random distribution in both series of tests.

From measured resonance frequency, the dynamic modulus of elasticity of the pear was calculated and described according to [38].

Second-order models [Eq. (9)] were used to fit the observed data. Determination of the dynamic modulus of elasticity of the pear and the correlation coefficient among dynamic properties and transmissibility of pear for three types of package are in Table (2). The coefficients of the model were calculated through nonlinear regression.

Table (1). Comparison of FDD and EFDD technique for determining resonance frequency and damping with three types of package.

\begin{tabular}{|c|c|c|c|c|c|c|}
\hline Mode & FDD (Hz) & EFDD (Hz) & $\eta_{(a)} \%$ & $\eta_{(b)} \%$ & $\eta_{(\mathrm{c})} \%$ & MAC \\
\hline 1,1 & 10 & 9.80 & 0.41 & 0.49 & 0.45 & 0.998 \\
\hline 2,1 & 20 & 19.9 & 0.32 & 0.37 & 0.34 & 0.996 \\
\hline 3,2 & 70 & 87.75 & 0.32 & 0.37 & 0.33 & 0.940 \\
\hline 4,2 & 150 & 150 & 0.37 & 0.39 & 0.38 & 0.996 \\
\hline 5,3 & 180 & 177 & 0.34 & 0.38 & 0.35 & 0.964 \\
\hline
\end{tabular}

(a):Random Distribution

(b): Absorber Sheet

(c): Line Distribution

\subsubsection{The correlation of dynamic characteristics of pear with transmissibility.}

Some characteristics revealed various values of coefficients of correlation among the dynamic characteristics and different type of packaging presented in Table (2). Transmissibility relationships with frequency at different type of packaging, it was noticed that highly negative and significant correlations $(\mathrm{P}<0.001)$ between transmissibility and frequency for random distribution, line distribution and absorber sheet package $(-0.999,-0.992$ and 0.926), respectively. These results mean that increasing transmissibility at low level of frequency as in Fig (8). This may be related to harmonic force from rotating part closed to natural frequency of the fruit this leads to increasing vibration and transmissibility, but when damping loss factor and dynamic modulus increased. transmissibility decreasing as shown in Fig (9\&10). 
The second order model [Eq. 9] was employed to establish correlations for transmissibility, young's modulus and packages method as shown in Fig (11). It was found to predict the transmissibility very well, as evident from the high correlation coefficient (0.948). The transmissibility for different packaging methods noticed that. First featured is that random distributed package is more transmissibility than line distributed and absorber sheet package. Second featured is that transmissibility increased with decreased young's modulus. It seems that absorber sheet package absorbed the impact between the fruits. Therefore, absorber sheet package is the best package method to reduce the damage between the samples during the transport.

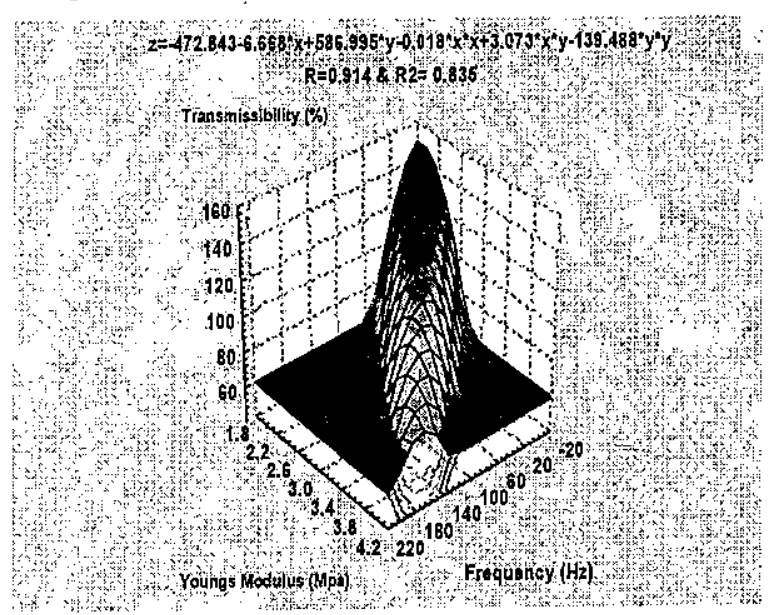

Fig. (8). Response surface of the transmissibility $(T)$ of pears as a function of young's modulus (E) and frequency (f).

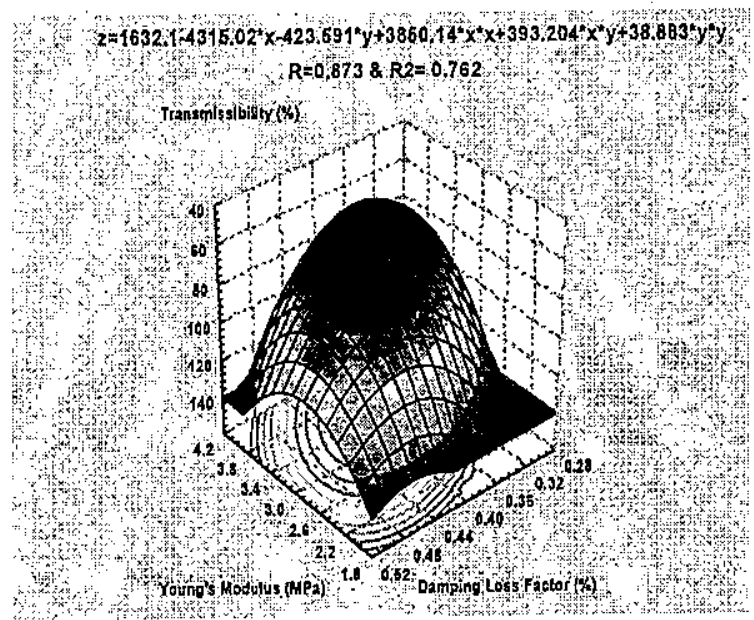

Fig. (9). Response surface of the transmissibility (T) of pears as a function of young's modulus $(\mathrm{E})$ and damping loss factor ( $\eta)$.

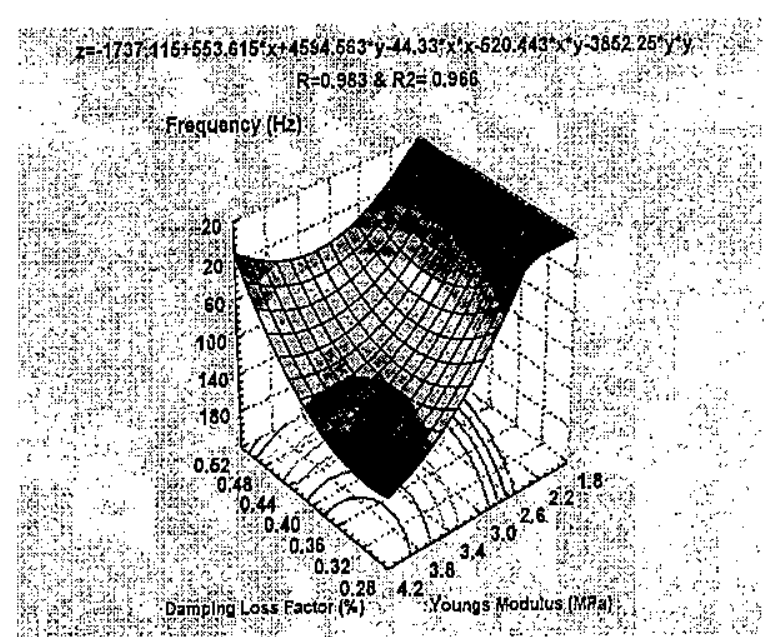

Fig. (10). Response surface of the frequency $(F)$ of pears as a function of young's modulus $(E)$ and damping loss factor $(\eta)$.

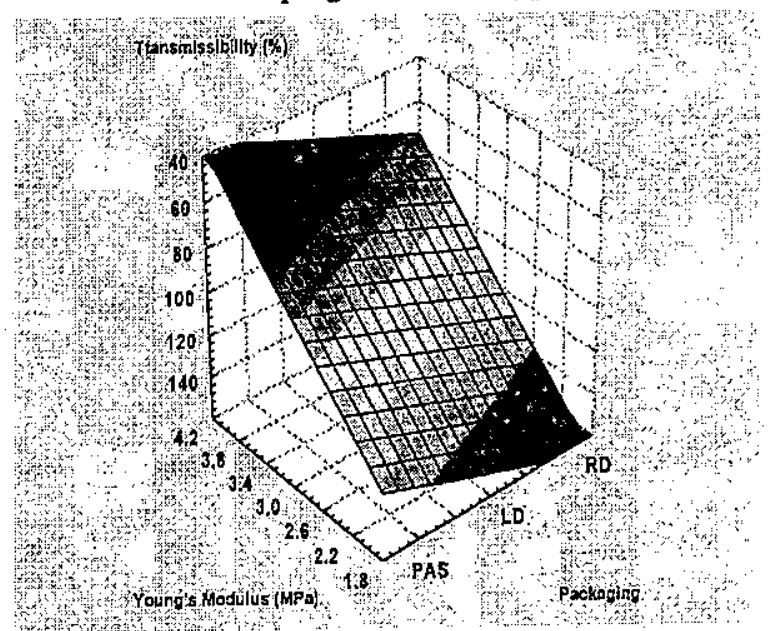

Fig. (11). Correlation of the transmissibility (T) of pears young's modulus (E) and packaging methods.

\subsection{Damage detection using a damage index.}

One of the objectives of this work is to obtain some reference data to detect damage state of fruit by comparing dynamic parameters obtained along transporting for three types of packing.

The damage state has been evaluated using the damage index method. A damage index can be used to quantify the change in dynamic properties of a structure in a potentially damage state compared to a baseline healthy state.

The damage index, $D_{i j}$ quantifies the aggregate change of the transmittance functions across a given of frequency range in terms of a scalar value. 
Table (2). Pearson correlation coefficients among.

\begin{tabular}{|c|c|c|c|c|c|}
\hline $\begin{array}{l}\text { Type of } \\
\text { Package }\end{array}$ & $\begin{array}{l}\text { Param } \\
\text { eters- }\end{array}$ & $\begin{array}{c}\text { Frequency } \\
(\mathrm{f}, \mathrm{Hz})\end{array}$ & $\begin{array}{l}\text { Damping Loss } \\
\text { Factor }(\eta, \%)\end{array}$ & $\begin{array}{l}\text { Elasticity (E, } \\
\mathrm{MPa})\end{array}$ & $\begin{array}{c}\text { Transmissibility ( } \mathrm{T}, \\
\%)\end{array}$ \\
\hline \multirow{4}{*}{$\begin{array}{c}\text { Random } \\
\text { Distribution }\end{array}$} & $(\mathrm{f}, \mathrm{Hz})$ & 1.000 & & & \\
\hline & $(\eta, \%)$ & -0.526 & 1.000 & & \\
\hline & $(\mathrm{E}, \mathrm{MPa})$ & $\begin{array}{l}0.991 \\
* * *\end{array}$ & -0.590 & 1.000 & \\
\hline & $(T, \%)$ & $\begin{array}{l}-0.999 \\
* * * \\
\end{array}$ & 0.511 & $\begin{array}{c}-0.987 \\
* *\end{array}$ & 1.000 \\
\hline \multirow{4}{*}{$\begin{array}{c}\text { Line } \\
\text { Distribution }\end{array}$} & $(\mathrm{f}, \mathrm{Hz})$ & 1.000 & & & \\
\hline & $(\eta, \%)$ & -0.369 & 1.000 & & \\
\hline & $(\mathrm{E}, \mathrm{MPa})$ & $\begin{array}{c}0.977 \\
* * \\
\end{array}$ & -0.410 & 1.000 & \\
\hline & $(\mathrm{T}, \%)$ & $\begin{array}{c}-0.992 \\
* * *\end{array}$ & 0.345 & $\begin{array}{c}-0.988 \\
* *\end{array}$ & 1.000 \\
\hline \multirow{4}{*}{$\begin{array}{c}\text { Vibration } \\
\text { Absorber } \\
\text { Sheet }\end{array}$} & $(\mathrm{f}, \mathrm{Hz})$ & 1.000 & & & \\
\hline & $(\eta, \%)$ & -0.708 & 1.000 & & \\
\hline & $(\mathrm{E}, \mathrm{MPa})$ & $\begin{array}{c}0.986 \\
* *\end{array}$ & -0.719 & 1.000 & \\
\hline & $(\mathrm{T}, \%)$ & $\begin{array}{c}-0.926 \\
*\end{array}$ & 0.754 & $\begin{array}{c}-0.887 \\
* \\
\end{array}$ & 1.000 \\
\hline
\end{tabular}

This scalar quantification eliminates the need to store the complete time history and or spectral data when data storage limitations are of concern. The damage index $D_{i j}$ defined over a frequency range of $f_{1}$ to $f_{2}$ is given as [31]:

$$
D_{i j}=\frac{\int_{f_{1}}^{f_{2}} \dot{T}^{h}{ }_{i j}(f)-T^{d}{ }_{i j}(f) / d f}{\int_{f_{1}}^{f_{2}} T^{h}{ }_{i j}(f) / d f}
$$

Where $T^{h}{ }_{i j}(f)$ : represents the transmittance function $T^{h}{ }_{i j}(f)$ of response point $(i)$ relative to response point $(j)$ in a healthy state, and $T^{d}{ }_{i j}(f)$ represents the transmittance function of response point $(i)$ relative to response point $(j)$ in a damage state. In the case of (damage pear), the desired outcome is to quantify the change in damage index relative to bruise area and volume. The damage indices were calculated over the entire $(0-200 \mathrm{~Hz})$ range. The frequency band from $(0-50 \mathrm{~Hz})$ was observed to produce the most sensitivity of the damage index of the bruise area (damage). A sample of transmittance function, for this frequency range is presented in Fig (12) based abound transmission scheme in Fig (4). The health state is represented by zero bruise area (damage) and damage stated plotted corresponds to variable area of bruise (random distribution, line distribution and absorber sheet) as in Fig (13). The repeatability of the transmittance test results was investigated in six separating trials as in Fig (14).

The tests showed damage indices calculated from transmittance function has some variation as shown in Table (3) and Fig (13). Fig (14) shows the variation in damage index from $(0.55$ to 0.61$)$ for random distribution which is approximately $6 \%$ of the smaller value. The other damage indices results lesser variation than random distribution. This damage may be due to fatigue due to repeated forces of vibration or friction dislocation on the pear (resulting in cell rupture) affecting the skin, intensity and duration of vibration. The result due to the possible effect according to position of pear inside the package and absorber sheet is as protective treatment as a cushioning package.

\subsubsection{Determining the effect of mechanical vibration and packing method on damage of peurs.}

This study was conducted to evaluate the effects of vibration frequency, vibration acceleration, packaging method, and vibration duration on the mechanical damage during pear transportation. The study was performed in two stages. Firstly, vibration frequency range $(0-50 \mathrm{~Hz}),(50-100 \mathrm{~Hz})$, and the auto power spectrum were measured on the model to study the effect of some factors (frequency, packaging and duration) on the mechanical damage during pear transportations, through the analysis of vibration spectrum of the interested frequency range. Secondly, wide range of vibration frequency (100- 
$200 \mathrm{~Hz}$ ) are sensitive for all packaging methods used in this study were measured, it is a range which is applied in most applied transporting. The band widths associated were based on previous study by [45], these band were chosen for concentrated frequency visually observed.

According to the measured results, Fig (12) and Table (4, 5\&6) shows the relation between auto power spectral density and frequency range (0-50 $\mathrm{Hz}),(50-100 \mathrm{~Hz})$ and $(100-200 \mathrm{~Hz})$ and at different packaging method. Some differences in auto PSD are evident as shown in Fig (12).

Fig $(12, a)$ at frequency range $(0-50 \mathrm{~Hz})$ the values of PSD in random packing are higher than the values in line distribution and absorber sheet packaging, this may be return to the method of packaging samples and the paper between the samples whose damped the vibration so the values decreased. For $(50-100 \mathrm{~Hz})$ range, the values of PSD decreased followed by the values at $(100-200 \mathrm{~Hz})$.
This is due to the presence of damping in absorber sheet (isolation medium) affects the response to shock, and can observe that when vibration frequency increased the values of PSD decreased.

Fig (15) shows that increasing in bruise volume (damage) for three methods of package in range (0$50 \mathrm{~Hz})$ compared to $(100-200 \mathrm{~Hz})$. This may be due to increase number of resonance frequencies in range $(0-50 \mathrm{~Hz})$ as shown in Fig (12), and this may be related to harmonic force from rotating element closed to natural frequency of pear, and this is very important factor in causing damage during transporting, these findings agreement with [35]. This need much attention in research, the importance of fruit natural frequency in design of the suspension system for fruit transport trucks in attempt to keep the resonance frequencies of the fruit away from exciting frequency of rotating system and to design cushioning package to protect an item (fruit) of known strength from known shock and vibration.

Table (3). The difference in \% of damage wall.

\begin{tabular}{|c|c|c|c|c|c|c|}
\hline \multirow[b]{2}{*}{$\begin{array}{l}\text { Type of } \\
\text { Package }\end{array}$} & \multirow[b]{2}{*}{$\begin{array}{c}\text { Frequency, } \\
(\mathrm{Hz})\end{array}$} & \multirow[b]{2}{*}{$\begin{array}{l}\text { Damage } \\
\text { Position } \\
(A, B, C)\end{array}$} & \multirow[b]{2}{*}{$\begin{array}{c}\text { Damage } \\
(\%)\end{array}$} & \multicolumn{3}{|c|}{ Change of damage skin } \\
\hline & & & & $\begin{array}{c}\text { Bruise } \\
\text { Area } \\
\left(\mathrm{cm}^{2}\right)\end{array}$ & $\begin{array}{l}\text { Bruise } \\
\text { Volume } \\
\left(\mathrm{cm}^{3}\right)\end{array}$ & $\begin{array}{c}\text { Bruise } \\
\text { Spot Ratio } \\
\text { (BSR, \%) }\end{array}$ \\
\hline \multirow{3}{*}{$\begin{array}{c}\text { Random } \\
\text { Distribution }\end{array}$} & $0-50$ & $B, C$ & 55 & 2.88 & 9.36 & 32 \\
\hline & $50-100$ & $\mathrm{~B}, \mathrm{C}$ & 58 & 2.21 & 7.41 & 32 \\
\hline & $100-200$ & $B$ & 61 & 2.05 & 4.21 & 31 \\
\hline \multirow{3}{*}{$\begin{array}{c}\text { Line } \\
\text { Distribution }\end{array}$} & $0-50$ & $B, C$ & 35 & 2.00 & 8.40 & 31 \\
\hline & $50-100$ & $\mathrm{~B}$ & 45 & 1.82 & 5.04 & 29 \\
\hline & $100-200$ & $\mathrm{~B}$ & 52 & 1.51 & 3.84 & 28 \\
\hline \multirow{3}{*}{$\begin{array}{c}\text { Vibration } \\
\text { Absorber Sheet }\end{array}$} & $0-50$ & $B$ & 15 & 1.44 & 5.45 & 30 \\
\hline & $50-100$ & $\mathrm{~B}$ & 22 & 1.12 & 3.86 & 28 \\
\hline & $100-200$ & B & 33 & 1.00 & 2.36 & 27 \\
\hline
\end{tabular}

Table (4). Descriptive Statistics of Vibration Analysis for Pears in Random Distribution Packaging at different Frequencies.

\begin{tabular}{|c|c|c|c|c|c|c|c|}
\hline \multirow{2}{*}{ Items } & \multirow{2}{*}{$\begin{array}{l}\text { Durration } \\
\text { time }\end{array}$} & \multirow{2}{*}{ Mean } & \multicolumn{2}{|c|}{ Range } & \multirow{2}{*}{ S. dev } & \multirow{2}{*}{ S.E. } & \multirow{2}{*}{ C.V.\% } \\
\hline & & & Min. & Max. & & & \\
\hline \multicolumn{8}{|c|}{$(0-50 \mathrm{~Hz})$} \\
\hline \multirow{2}{*}{$\begin{array}{c}\text { P.S.D } \\
\left(\mathrm{dB}^{2} / \mathrm{Hz}\right)\end{array}$} & 5 & 30 & 1.00 & 136.46 & 33.31 & 8.60 & 28.66 \\
\hline & 10 & 31.49 & 7.69 & 164.06 & 32.16 & 8.30 & 26.36 \\
\hline \multicolumn{8}{|c|}{$(50-100 \mathrm{~Hz})$} \\
\hline \multirow{2}{*}{$\begin{array}{c}P . S . D \\
\left(\mathrm{~dB}^{2} / \mathrm{Hz}\right)\end{array}$} & 5 & 15.06 & 5.15 & 98.30 & 17.22 & 4.45 & 29.52 \\
\hline & 10 & 18.06 & 13.84 & 91.65 & 14.39 & 3.71 & 20.58 \\
\hline \multicolumn{8}{|c|}{$(100-200 \mathrm{~Hz})$} \\
\hline \multirow{2}{*}{$\begin{array}{c}P . S . D \\
\left(\mathrm{~dB}^{2} / \mathrm{Hz}\right)\end{array}$} & 5 & 18.96 & 9.92 & 89.38 & 13.74 & 3.55 & 18.71 \\
\hline & 10 & 4.09 & 2.15 & 16.53 & 2.01 & 0.52 & 12.67 \\
\hline
\end{tabular}




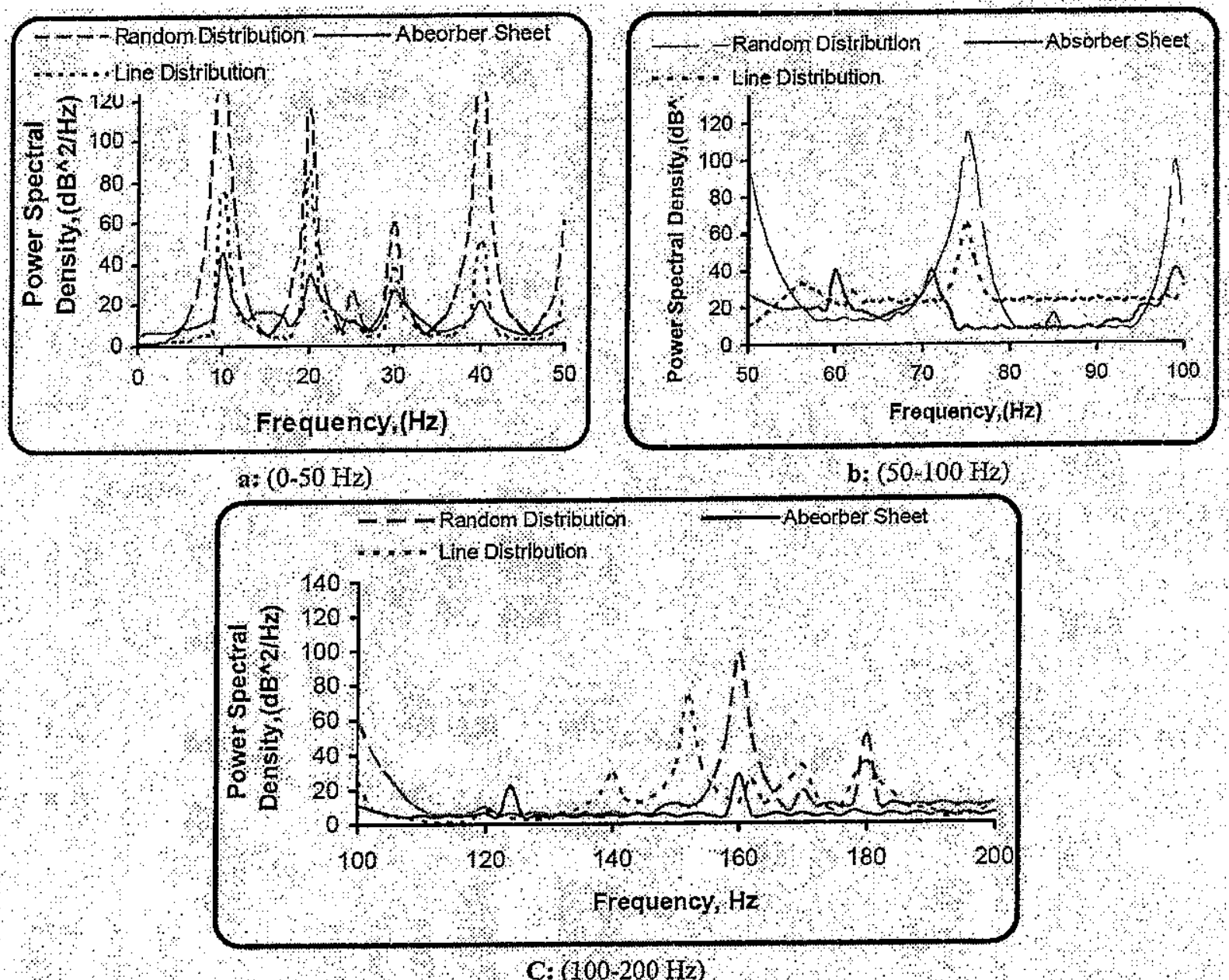

Fig. (12) Relationship between Power Spectral Density $\left(\mathrm{dB}^{\wedge} 2 / \mathrm{Hz}\right)$ and Frequency $(\mathrm{Hz})$ for Pears at three level of vibration (0-50), (50-100),(100-200) Hz for variable packaging methods (absorber sheet, line distributed and random distribution).

Table (5). Descriptive Statistics of Vibration Analysis for Pears in Vibration Absorber. Sheet packaging at different Frequencies.

\begin{tabular}{|c|c|c|c|c|c|c|c|}
\hline \multirow{2}{*}{ Items } & \multirow{2}{*}{$\begin{array}{l}\text { Duration } \\
\text { time }\end{array}$} & \multirow{2}{*}{ Mean } & \multicolumn{2}{|c|}{ Range } & \multirow{2}{*}{ S. dev } & \multirow{2}{*}{ S.E. } & \multirow{2}{*}{ C.V.\% } \\
\hline & & & Min. & Max. & & & \\
\hline \multicolumn{8}{|c|}{$(0-50 \mathrm{~Hz})$} \\
\hline \multirow{2}{*}{$\begin{array}{c}\text { P.S.D } \\
\left(\mathrm{dB}^{2} / \mathrm{Hz}\right)\end{array}$} & 5 & 13.24 & 4.61 & 45.71 & 8.04 & 2.07 & 15.68 \\
\hline & 10 & 23.76 & 10.38 & 33.20 & 3.81 & 0.98 & 4.14 \\
\hline \multicolumn{8}{|c|}{$(50-100 \mathrm{~Hz})$} \\
\hline \multirow{2}{*}{$\begin{array}{c}P . S . D \\
\left(\mathrm{~dB}^{2} / \mathrm{Hz}\right)\end{array}$} & 5 & 5.49 & 4.06 & 22.06 & 2.73 & 0.70 & 12.82 \\
\hline & 10 & 9.14 & 3.58 & 64.06 & 11.45 & 2.96 & 32.36 \\
\hline \multicolumn{8}{|c|}{$(100-200 \mathrm{~Hz})$} \\
\hline \multirow{2}{*}{$\begin{array}{c}P . S . D \\
\left(\mathrm{~dB}^{2} / \mathrm{Hz}\right)\end{array}$} & 5 & 5.13 & 4.06 & 9.91 & 1.15 & 0.30 & 5.79 \\
\hline & 10 & 15.13 & 13.84 & 45.71 & 4.25 & 1.08 & $7.25^{\circ}$ \\
\hline
\end{tabular}


Table (6). Descriptive Statistics of Vibration Analysis for Pears in Line Distribution Packaging at different Frequencies.

\begin{tabular}{|c|c|c|c|c|c|c|c|}
\hline \multirow{2}{*}{ Items } & \multirow{2}{*}{$\begin{array}{c}\text { Duration } \\
\text { time }\end{array}$} & \multirow{2}{*}{ Mean } & \multicolumn{2}{|c|}{ Range } & \multirow{2}{*}{ S. dev } & \multirow{2}{*}{ S.E. } & \multirow{2}{*}{ C.V.\% } \\
\hline & & & Min. & Max. & & & \\
\hline \multicolumn{8}{|c|}{$(0-50 \mathrm{~Hz})$} \\
\hline \multirow{2}{*}{$\begin{array}{c}\text { P.S.D } \\
\left(\mathrm{dB} / \mathrm{Hz}^{2}\right)\end{array}$} & 5 & 11.49 & 1.14 & 85.11 & 16.95 & 4.38 & 38.08 \\
\hline & 10 & 20.35 & 6.37 & 58.77 & 13.84 & 3.57 & 17.56 \\
\hline \multicolumn{8}{|c|}{$(50-100 \mathrm{~Hz})$} \\
\hline \multirow{2}{*}{$\begin{array}{c}\text { P.S.D } \\
\left(\mathrm{dB} / \mathrm{Hz}^{2}\right)\end{array}$} & 5 & 12.14 & 1.50 & 43.41 & 10.03 & 2.59 & 21.35 \\
\hline & 10 & 19.39 & 16.08 & 40.58 & 5.12 & 1.32 & 6.82 \\
\hline \multicolumn{8}{|c|}{$(100-200 \mathrm{~Hz})$} \\
\hline \multirow{2}{*}{$\begin{array}{c}P . S . D \\
\left(\mathrm{~dB} / \mathrm{Hz}^{2}\right)\end{array}$} & 5 & 12.72 & 2.24 & 85.11 & 13.33 & 3.44 & 27.06 \\
\hline & .10 & 8.56 & 2.52 & 85.11 & 11.10 & 2.87 & 33.48 \\
\hline
\end{tabular}

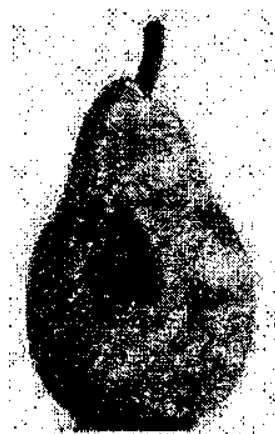

Vibration obsorberisieet

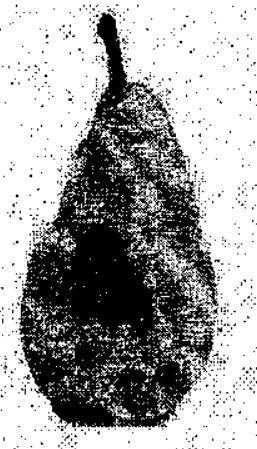

Live: distribution

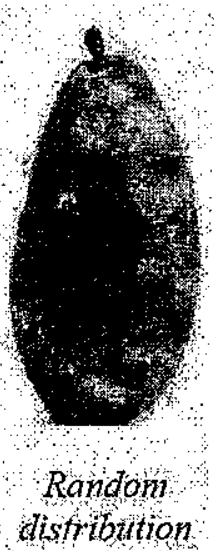

disfribution:
Fig (13). The difference in percent of damage

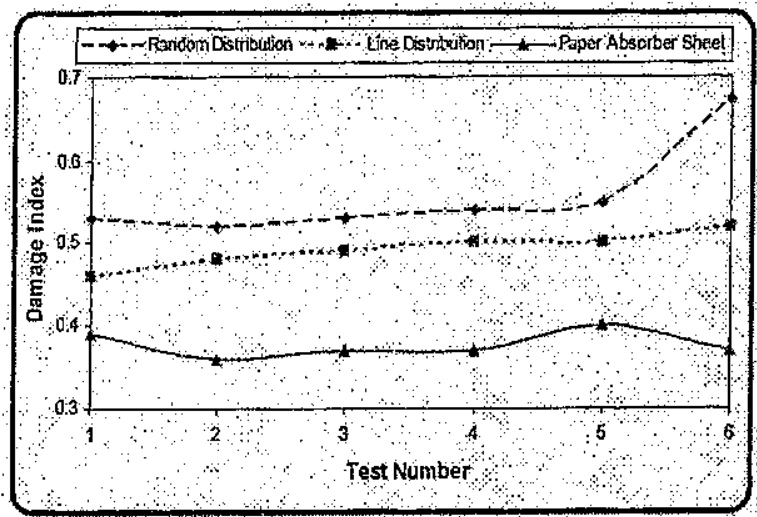

Fig (14). Repeatability of computing damage index using Transmittance function.

\subsubsection{Effect of packaging method on number of Pear bruise at different vibration frequencies.}

The bruise spots have characteristic shapes expressed by bruise spot ratio (BSR), the ratio of the bruise spot thickness (t) to the bruise spot diameter (d). Our results are concentrated in Table (3). The bruises obtained in the package absorber sheet had rather lower bruise spot ratio than the random and line distribution package.

Simulations were executed to quantify the effect of packaging method on mechanical damage during transport of pear. In the simulations the size of the box in the simulations was equal to $0.6 \times 0.4 \times 0.2 \mathrm{in}$ leading to a stack height of $20 \mathrm{~cm}$.

Data presented in Fig (15) showed that decreasing in the bruise volume (damage) at different packaging methods at increasing vibration frequency from $(100-200 \mathrm{~Hz}$ ), but by investigating (number of damage pear) Fig (16) at low frequency $(0-50 \mathrm{~Hz})$ is less than (100-200 Hz). This result indicates that the occurred damage depend on the dynamic

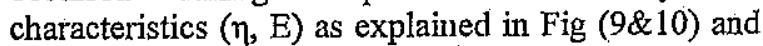
Table (2). Fig (16) shows the effect frequency on number of pear bruise at different packaging at duration time $5 \mathrm{~min}$ and $10 \mathrm{~min}$. The results in Fig (16) showed that for the main factors, the absorber sheet packaging was the best method of interior packaging, followed by line distribution produced the highest damage level. The vibration duration of (10 $\mathrm{min}$ ) caused damage levels higher than $(5 \mathrm{~min}$ ) for all distribution methods, which means that high bruise dimensions in the pear containers were increased by an increase in vibration duration. The test results obtained in this study were similar to those obtained by [46] reported that an increase in the distance traveled raised the percentage of fruit bruised during transportation.

Fig (16) shows that the number of bruised pears increased by increasing frequencies and vibration durations $(5-10 \mathrm{~min})$. Therefore, most of the vibration forces transmitted from the vibration table to the Pears container are absorbed by the Pears in the containers and cause bruising of the Pears. The reason for these bruises can be attributed to the fact that such forces in the Pears are higher, causing some 
of the Pears to be periodically weightless. Weightlessness allowed the Pears to rotate and to bump against each other. This movement caused the surface discoloration and cell 'wall fatigue, and consequently bruising damage in Pears according to [36].

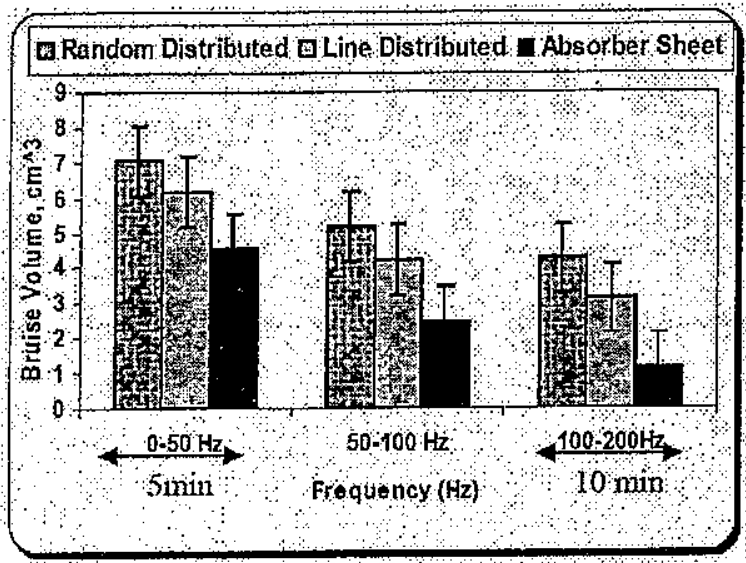

Fig. (15) Effect of packaging method on the bruise volume of pears at different vibration frequencies.

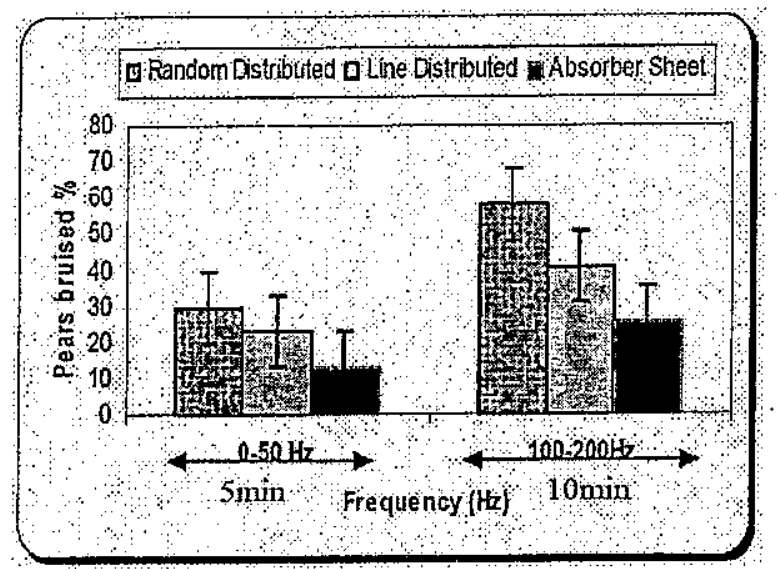

Fig. (16). Effect of vibration frequency on the number of pear bruised at different packaging method.

\section{CONCLUSION}

1. The vibration absorber sheet shows the practical use of vibration absorber as a quality assessment technique for pear during transporting and handling. The use of vibration absorber sheets appears to reduce the percentage of damaged fruit by about $46-59 \%$, eliminating the alterations due to contact with the other fruit and bottom of the box.

2. There is a difference in percentage of damage wall in fruits according to this investigators transport damage refer to roller bruising it is important factor affecting the quality of fresh and processed fruit.

3. Fruit bruising is one of the most important factors limiting mechanization and automation in harvesting, sorting and transport of soft fruit and vegetables. Bruise extent is usually described in terms of bruise volume, which is closely related to product quality. The most important bruise factor in every case is the loading extent, which is usually expressed in the terms of loading energy or absorbed energy.

4. The technique allows a very fast measurement online (OMA) technique allows a scientist, technician, or engineer to perform a modal investigation easily, quickly and accurately. It can be accomplished by only measuring the response of the structure subjected to unknown and unmeasured force furthermore, since the technique is based on the vibration of the pear as a whole, a global quality parameters is found, this in contrast with several classical techniques that are used to assess fruit quality (for instance penetrometer or firmness values) that only give local information.

5. Due to the damping characteristic of pear and effect of intersect of dominant harmonic component in the measured responses (which is unavoidable in many applications of OMA). EFDD is a robust estimation of the resonant frequency of the five bending modes and damping ratio was used, based on smoothing of the frequency spectrum (coherence) and spaced mode to sure that there are not leakage exist and there for the inverse test time are successively obtairied.

6. The dynamic characteristics of the fruit species is an important factor in determining the causes of in transient fruit damage during transporting, this need much attention in research, the importance of fruit natural frequency in design of the suspension system for fruit transport trucks in attempent to keep the resonance frequencies of truck away from the range of fruit resonance frequency and to design cushioning package to protect an item (fruit) of known strength from known shock and vibration.

\section{REFERENCES}

[1]. Abbott, J.A., Lu, R., 1996. Anisotropic mechanical properties of apples. Transactions of the ASAE, 39(4):1451-1459.

[2] Chen, H., de Baerdemaeker, J., (1993). Modal analysis of the dynamic behavior of pineapples and its relation to fruit firmness. Transactions of the ASAE, 36(5):1439-1444.

[3] Wang, J., Sheng, K.C., 2005. Variations in firmness and sugar content in 'Huanghua' pear (Pyrus pyrifolia 'Nakai'). Journal of Horticultural Science and Biotechnology, 80(3):307-312. 
[4] Abbott, A.J., Affeldt, A.H., Liljedahl, A.L., 1992. Firmness measurement of stored 'Delicious' apples by sensory methods, Magness-Taylor, and sonic transmission. Journal of the American Society for Horticultural Science, 117:590-595.

[5] Schotte, S., de Belie, N., de Baerdemaerker, J., 1999. Acoustic impulse-response technique for evaluation and modeling of firmness of tomato fruit. Postharvest Biology and [doi:10.1016/S0925-5214(99) Technology, 17(2):105-115.00041-1]

[6] De Belie, N., Schotte, S., Coucke, P., de Baerdemaerker, J., 2000. Development of an automated monitoring device to quantify changes in firmness of apple during storage. [doi:10. Postharvest Biology and Technology, 18(1):1-8.

[7] Wang, J., 2003. Anisotropic relaxation properties of pear. [doi:10.1016/ Biosystems Engineering, 85(1):59-65.S1537-5110(03)00017-5]

[8] Wang, J., Teng, B., Yu, Y., 2004a. Pear dynamic characteristics and firmness detection. European Food Research and [doi: 10.1007/s00217-003Technology, 218(3):289-294.0850-9]

[9] Wang, J., Teng, B., Zhou, M., 2004b. Dynamic response of impact forces on pear. Transactions of the Chinese Society for Agricultural Machinery, 35(2):65-68.

[10] Abbott, J. A., Massie, D. R., Upchurch, B. L., \& Hruschka, W. R. (1995). Non-destructive sonic furmness measurement of apples. Transactions of ASAE, 38(5), 1461-1466.

[11] Galili, N., Mizrach, A., \& Rosenhouse, G. (1993). Ultrasonic testing of whole fruit for nondestructive quality evaluation. Transactions of ASAE, 36, 345-351.

[12] Bellon, V., Vigneau, J. L., \& Crochon M. (1993). Nondestructive sensing of peach firmness. In Proceedings of IV international symposium on fruit, nut and vegetables production engineering (vol. 2, pp. 291-297). Valencia-Zaragoza: Spain.

[13] Dewulf, W., Jancsok, P., Nicolaï, B.M., de Roeck, G., Briassoulis, D., 1999. Determining the firmness of a pear using finite element modal analysis. Journal of Agricultural [doi:10.1006/jaer. Engineering Research, 74(3):217-224.1999.0451]

[14] Jancsok, P.T., Clijmans, L., Nicolai, B.M., de Baerdemaeker, J., 2001. Investigation of the effect of shape on the acoustic response of 'conference' pears by finite element modeling. Postharvest Biology and Technology, 23(1): 112.

[15] Song Hui-zhi, Wang Jun, LI Yong-hui (2006). Studies on vibration characteristics of a pear using finite element method. $J$ Zhejiang Univ SCIENCE B, 7(6):491-496.

[16] Hinsch, R.T., Slaughter, D.C., Craig, W.L., Thompson, J.F., 1993. Vibration of fresh fruits and vegetables during refrigerated truck transport. Trans. ASAE 36,1039-1042.

[17] Jarimopas, B., Singh, S.P., Saengnil, W., 2005. Measurement and analysis of truck transport vibration levels and damage to packaged tangerines duringtransit.Packag.Technol.Sci.18, 179-188.

[18] Turczyn, M.T., Grant, S.W., Ashby, B.H., Wheaton, F.W., 1986. Potato shatters bruising during laboratory handling and transport simulation. Trans. ASA 29,1171-1175.

[19] Vergano, P. J., Testin, R.F., NewallJr., W.C.,1991. Peach bruising: susceptibility to impact, vibration, and compression abuse. Trans.ASAE 34, 2110-2116.

[20] Timm, E.J., Brown, G.K., Armstrong, P.R., 1996. Apple damage in bulk bins during semitrailer transport. Appl.Eng.Agric.12, 369-377.

[21] Van Zeebroeck, M., Tijskens, E., Dintwa, E., Kafashan, J., Loodts, J., De Baerdemaeker, J.,Ramon,H., 2006.The discrete element method (DEM) to simulate fruit impact damage during transport and handling: Model building and validation of $\mathrm{DEM}$ to predict bruise damage ofapples. PostharvestBiol. Technol.41,85-91.

[22] Barchi, G. L., (2002). Damage to loquats by vibration simulating intra stale transport. Biosystems Engineering. 82(3):305-312.

[23] Berardinelli, A., Donati, V., Giunchi, A., Guarnieri, A., Ragni,L., (2005). Damage to pears caused by simulated transport. J. Food Eng. 66, 219-226.

[24] Remon, S., Venturini, M.E., Lopez-Buesa, P., Rosa, O., 2003. Burlat cherry quality after long range transport: optimization of packaging conditions.

InnovativeFoodSci.Emerg. Technol.4,425-434.

[25] Mohanty, P. and Rixen, D. J. (2004). Operational modal analysis in the presence of harmonic excitation. Journal of sound and vibration. 270: 93-109.

[26] Brownjohn JMW, (2003). Ambient vibration studies for system identification of tall building. Earthquake Engineering and Structural Dynamics. 32:71-95.

[27] Brincker R. L. Zhang, P. Anderson, (2001). Model identification of output only system using frequency domain decomposition smart materials and structures. 10:44-50.

[28] Galvin, P. J. Domingues, (2007). Dynamic analysis of cable-stayed deck steel arch bridge. 
Journal of Constructional Steel Research. 63:1024-1035.

[29] Schwarz, B., and M. H.Richarson, (2001). Modal parameter estimation from ambient response data. Presented at IMAC 5-8 February. P: 1017-1022.

[30] Jacobsen, N. J., (2006). Separating structural Models and Harmonic Components in OMA IMAC XXIV.

[31] Caccese, V., Mewer. R., and Vel, S., (2004). Detection of bolt loss in hybrid composite metal bolted connections. Engineering Structures. 26:895-906.

[32] Pai, P. F.; Young, L. G. (2001). Damage Detection of Beams using Operational Deflection Shapes. Int. J. Solids and structures: 38(18), 3161-3192.

[33] Batel, M. (2002). Operational modal analysis another way of doing modal testing. Bruel \& Kjaer, Norcross, Georgia. Sound and Vibration/August,P: 22-27.

www.sandv.com/downloads/0208batl.pdf.

[34] Jacobsen N. J., P. Anderson, and R. Brincker, (2007). Using enhanced frequency domain decomposition Robust technique to harmonic exaltation in operational modal analysis. Bruel \& Kjaer, Norcross, Georgia. Sound and Vibration Measurement A/S, P: 1-12.

$\mathrm{ftp} / / / \mathrm{ttp}$.svids.com/download/literature/papers/20 $06 / 2006$ 6.pdf.

[35] Ran Zhou, Shuqiang Su, Liping Yan, Yunfei Li. (2007). Effect of transport vibration levels on mechanical damage and physiological response of Huanghua pears. Post-harvest Biology and Technology. 46:20-28.

[36] Vursavus. K.; F. Ozgoven (2004). Determining the Effects of Vibration Parameters and Packaging Method on Mechanical Damage in Golden Delicious Apples.Turk J Agric For,28:311-320.
[37] Brincker, R., L. Zhang, and P. Anderson, (2000). Modal identification from ambient response using frequency domain decomposition. Proc. Of the $18^{\text {th }}$ int. modal Analysis Conference. San Antonio TX, 7-10 Feruary.

[38] Amer Essa A.H. and Gomaa. F. R. (2007). Prediction of fracture of eggshell using operational modal analysis. Engineering Research Journal, Minoufiya Úniversity, Vol.30, No.1, PP 77-88.

[39] Dascotte, 1. E. (2002). Material Identification of Composite Structure from the combined use of FEA and Experimental Modal Analysis. Dynamic Engineering N.V.

[40] Coucke P., B. De Ketelaere, J De Baerdemeker, (2003). Experimental analysis of dynamic , mechanical behavior of chicks egg. Journal of sound and vibration. 266:711-721.

[41] Bendat, Julius S. and Piersol, Allan G., (1986). Random Data Analysis and Measurement Procedure, John Wiley and Sons.

[42] Schoorl, D.,Holt, J.E.,1977. The effects of storage time and temperature on the bruising of Jonathan, delicious and Granny Smith apples. J. Texture Stud. 409-416.

[43] Barreiro, P., 1999. Detailed procedure for fruit damaging. ASTEQ CA Newsletter No.2,pp.3-5.

[44] Boswall, P. (2002). Potato shatter bruise test using Catechol. Website: www.gov.pe.ca/af/agweb

[45] Armstrong, P. R; Stone M. L.; Brusewitz G. H. (1997). Nondestructive acoustic and compression measurements of watermelon for internal damage detection. Applied Engineering in Agriculture. Vol. 13(5): 641-645.

[46] Schulte, N. L., E.J. Timm, G. K. Brown, D. E. Marshall and C. L. Burton (1990). Apple damage assessment during intrastate transportation. Applied Engineering in Agriculture $_{;}$6: 753-758. 